\title{
EL TEATRO TRÁGICO DE MARÍA ROSA GÁLVEZ DE CABRERA EN EL TRÁNSITO DE LA ILUSTRACIÓN AL ROMANTICISMO: UNA UTOPÍA FEMENINA Y FEMINISTA
}

Helena EstabliER Universidad de Alicante

Fue María Rosa Gálvez de Cabrera mujer de vida singular y sin duda poco ortodoxa para la época en la que se obstinó en ser dramaturga. Nacida a finales del año 1768 -o quizá a principios del año siguiente-, no tuvo una vida muy larga, ya que falleció en 1806 a la edad de treinta y ocho años, dejando, eso sí, una lista asombrosa -por el número y la variedad- de obras dramáticas, que no iguala ninguna otra autora de su tiempo. Sabemos de ella que fue hija adoptiva en el hogar de los Gálvez, ilustre familia andaluza de políticos y militares, siendo posiblemente su padre adoptivo también su padre biológico; sabemos también que contrajo matrimonio en 1789 con un Teniente de Infantería aficionado al juego, que le proporcionó no pocos sinsabores personales y económicos, y de quien se separó en diversas ocasiones hasta 1803 , fecha en que él marchó como agregado a la secretaría del Ministerio español en los Estados Unidos. Sabemos también que murió sin descendencia, y que tuvo una única hija que falleció en plena infancia. Aunque es posible reconstruir sus avatares económicos y matrimoniales por los documentos legales y notariales de los que se dispone, no contamos apenas con información sobre sus años de formación' ${ }^{1}$, pero parece posible suponer, a la vista

La más exhaustiva investigación biográfica sobre ella con la que contamos es la que realiza J. Bordiga en su tesis, que revisa y actualiza en La rosa trágica de Málaga: vida y obra de Maria Rosa Gálvez (2003); este estudio reciente resulta especialmente valioso en lo que respecta a la documenta- 
de su producción literaria, que tuvo una instrucción adecuada para una joven de buena familia, educación que ella complementó con una notable inspiración dramática, una más que notable voluntad de trabajo y un afán de gloria desbordante, que destaca poderosamente sobre la humildad acostumbrada en las escritoras de su tiempo.

Mujer sola en una España que pretendía a toda costa salvaguardar la institución matrimonial, tanto por la vía ilustrada como por la religiosa, prolífica en su escritura y deseosa a toda costa de ganar sustento y fama con su pluma, María Rosa Gálvez brilla con unas cualidades que la hacen destacar notablemente por encima de las colegas de su género y que la vuelven, por lo visto, muy sospechosa a los ojos de la crítica. De hecho, la escritora es conocida por una leyenda negra inaugurada por Guillén Robles (1874, pág. 681) en el siglo XIX, que la sitúa leyendo sonetos a Godoy a la hora matutina del chocolate. Esta leyenda, no confirmada por ninguna otra fuente, es retomada inmediatamente por Serrano y Sanz en sus Apuntes (I, CCLXIX, pág. 445), que añade que los versos en cuestión eran «lozanos y verdes» aunque nos previene contra la maledicencia que podría «haber exagerado notablemente los hechos», y es enriquecida posteriormente por Ezquerra del Bayo (1924), Margarita Nelken (1930), Paloma Fernández Quintanilla (1981), entre otros, y repetida, como hacemos hoy, por todos los que nos hemos referido a María Rosa Gálvez con el afán de poner sobre el tapete los prejuicios que una mujer, de vida y obra poco ortodoxas como las suyas, podía generar. En cualquier caso, y al margen de la invención de Guillén Robles, exitosa por el morbo innegable que destila esa imagen -con un grabado de Fragonard, la compara Nelken (pág. 182)-- de María Rosa Gálvez leyendo versos al Príncipe de la $\mathrm{Paz}$ en deshabillé mientras éste disfruta de su chocolate, es cierto que la escritora contó con el apoyo de Godoy, a quien solicitó en diferentes momentos prebendas relacionadas con pagos y exenciones de los mismos con motivo de la impresión de sus obras.

En general, la valoración que la crítica ha realizado sobre su obra es desconcertante por su falta de acuerdo ${ }^{2}$. Me parece, por tanto, necesario insistir en la

ción aportada y descubierta por la investigadora sobre los hechos fundamentales de la vida personal y literaria de María Rosa Gálvez, que le permiten reconstruir en buena medida las razones íntimas de una producción dramática que muchas veces se explica y se justifica en la experiencia biográfica de la autora. Antes de esto, J.R. Jones ya se había interesado por la biografia de esta escritora en «María Rosa de Gálvez: Notes for a Biography»(1995).

${ }^{2}$ Algunos de los primeros críticos la califican de imitadora de Moratín o insisten en su mediocridad, como J. Cejador y Frauca (1917), J. Cook (1974), J. L. Alborg (1972) -que declara incluirla en su Historia de la literatura española «a título de curiosidad»- y también otros críticos actuales, como J.A. Ríos (1995), que le dedica unas bien merecidas páginas a la escritora en la Historia de la Literatura Española coordinada por G. Carnero, indicando que «tuvo el defecto de escribir demasiadas obras en poco tiempo y sin seleccionar adecuadamente los géneros» (pág. 54L). Frente a esto, 
originalidad y la excepcionalidad de esta escritora, en la valoración de cuya obra deben entrar criterios que vayan más allá de su adecuación o no a la dramaturgia neoclásica, o su mayor o menor capacidad dramática para construir obras que alcancen el nivel de perfección artística que se les atribuye a las que configuran el «canon» de la comedia y de la tragedia neoclásicas. Conviene tener presente, en cualquier caso, que las obras de Gálvez se inscriben en un período -el de entresiglos- en el que la rigidez del esquema dramático «neoclásico» va cediendo a las nuevas exigencias sentimentales de tipo romántico, dando lugar, por un lado, a la comedia burguesa de desenlace feliz con una sensibilidad romántica en estado embrional y, por otro, a una nueva concepción de la tragedia contagiada del espíritu de la filosofía sensualista imperante, que permite prefigurar en cierta medida el drama histórico del Romanticismo. Es precisamente esta «ambigüedad» propia del momento de transición en el que se desarrolla su actividad dramática, la que nos debe servir para comprender la posible falta de adecuación de las obras de Gálvez a nuestras expectativas de la comedia y tragedia neoclásicas, permitiéndonos una valoración más ajustada del significado que alcanzan no sólo en el teatro de su tiempo sino en nuestra perspectiva actual sobre éste ${ }^{3}$.

Fernando Doménech (1996) nos dice que era una mujer «extraordinariamente dotada para el teatro, capaz de tratar todos los géneros poéticos de su época» (pág. 400), E. Palacios Fernández (2002) la califica como «la dramaturga más destacada de su tiempo, que lucha en igualdad de condiciones con los varones de tendencia neoclásica e ilustrada» (pág. 216) y R. Andioc (2001) habla de ella como «una escritora original no desprovista de talento»(pág. 100).

${ }^{3}$ Algunos estudiosos se han interesado recientemente por la obra de Gálvez desde diversas orientaciones críticas. Para obtener una perspectiva global de la obra de Gálvez resulta de gran ayuda la revisión general que realiza J. Bordiga en la obra ya citada (2003) de su traducción, su poesía y su obra dramática original, aunque esa globalidad va en detrimento en muchas ocasiones de la profundidad del análisis. También otros investigadores, fundamentalmente desde el hispanismo norteamericano, han tratado en mayor o menor medida la obra de María Rosa Gálvez, muy tempranamente E. Kahiluoto Rudat, que en 1986 dedica unas páginas pioneras a estudiar las ideas de Gálvez sobre el teatro neoclásico, y en la década de los noventa J. R. Jones (1995 y 1996), E. Franklin Lewis (1996 y 1997) y D. Whitaker (1988, 1990, 1992a, 1992b, 1993a y 1993b) que en diferentes artículos han explorado diversas tragedias y comedias de la escritora, aplicando-especialmente el último- las aportaciones teóricas de la crítica feminista y reivindicando para estas obras de Gálvez el reconocimiento que les ha faltado durante años en la historia del teatro español. También M. P. Zorrozua (1999), en su tesis sobre las escritoras españolas de la Ilustración, revisa desde una perspectiva fundamentalmente descriptiva la poesía y el teatro de $\mathrm{M}^{\mathrm{a}}$ Rosa Gálvez, E. Palacios Fernández (2002) le dedica también su atención en su libro sobre la mujer y las letras en el siglo XVIII y E. Franklin Lewis ha vuelto sobre la autora dedicándole un capítulo en su libro de 2004 Women writers in the Spanish Enlightenment. The pursuit of hapiness. Por su parte, F. Doménech (1995) y R. Andioc (2003) son los únicos que se han lanzado a la edición actual de algunas de sus obras y los estudios introductorios, especialmente el de Andioc, son de gran ayuda. 
Como autora de teatro original ${ }^{4}$, resulta sorprendente su versatilidad a la hora de participar en diferentes géneros, con mayor o menor incidencia de elementos populares. Creo que, para ser adecuadamente comprendida, esta capacidad para ensayar diversos géneros debe ser puesta en relación con la tensión que experimenta la autora entre la necesidad de convertir el teatro en medio de vida -que se trasluce perfectamente de las cartas que escribe solicitando prebendas económicas ${ }^{5}$ - y su deseo de labrarse un hueco como mujer escritora en la cumbre del Parnaso", afán de gloria que mal puede esconder por debajo del preceptivo

+ María Rosa Gálvez se ejercita también en el arte de la traducción del teatro francés con tres obras, posiblemente estimulada por el Plan de Reforma de Teatros de 1799 y por los derechos económicos que la colección «Teatro Nuevo Español» preveía para los autores de obras traducidas, similares a los de las obras originales («Prólogo al volumen I, págs. xiii-xiv). La primera es Calalina o La bella labradora, traducción de la comedia en prosa y tres actos del mismo título de Amćlie Candeille (Catherine ou la belle fermière), de tema sentimental y final moral, publicada en el tomo $V$ del Teatro Nuevo Español y representada en el teatro de la Cruz en septiembre de 1801, obra por la que las habilidades como traductora de María Rosa Gálvez recibieron una crítica demoledora del Menorial Literario el 11 de diciembre ese mismo año (la recoge Bordiga (2003, págs. 149-150). No se arredró la autora por tales críticas, y un año más tarde se representa en el Teatro de la Cruz $L a$ intriga espistolar, traducción de la comedia costumbrista en verso y tres actos de Fabre d'Églantine (L'intrigue epistolaire), donde se plantea un tema muy de época como es el de la libertad de casamiento de los jóvenes. Finalmente, en mayo de 1803 se estrena en el Teatro de los Caños del Peral y se publica en el primer tomo de sus Obras Poéticas la traducción libre de la opereta en verso Bion, escrita por François-Benoît Hoffman y con música de Étienne-Nicolas Méhul. No dejan de resultar interesantes, a la hora de estudiar el paso de Gálvez de la práctica de la traducción a la creación propia y su identificación con la imagen de autora de «tragedias originales», las manifestaciones que realiza en contra de la traducción y su reconocimiento del enorme perjuicio que ésta causaba al desarrollo del arte dramático español, tanto en su «Advertencia» al segundo volumen de sus Obras Poéticas como en su propio teatro. Recordemos, si no, los versos del Barón de la Ventolera en Los figurones literarios: «(...) Las traducciones/ Todos beaucoup, mucho, alaban./ Aunque sea el original/ Detestable, aunque estén mancas/ De los pies, aunque estén cojas/ De una mano; aunque no haya/ cabeza en ellas; aunque/ Sean ellas de moral mala, Inverosimiles; bueno:/ Son traducciones, pues basta» (Obras Poéticas, tomo I, pág. 274).

${ }^{5}$ En 1801, en carta a la Junta de la Dirección de Teatros para solicitar por su tragedia Ali-Bek el premio del tres por ciento estipulado para las tragedias originales, dice que «ha experimentado crecidas perdidas en sus rentas de resultas de la última desgraciada epidemia de Cádiz», y pide «se sirvan por esta vez (...) concederla el premio de veinticinco doblones por una vez, con renunciación del tres por ciento, o bien el que juzguen digno de la tragedia». En carta de 1803, explica que no tienc con qué costear los gastos de imrpresión de sus Obras Poéticas y solicita que ésta se realice en la Real Imprenta para reintegrar más adelante su coste. Finalmente, en carta de 1804 solicita se le perdone el coste de la impresión ya que dice estar «sumergida en la misma indigencia que antes de conseguir su primera gracia»(Bordiga, págs. 147 y 158).

' «Mi genio aspira a verse colocado/ En el glorioso templo de la fama», dice en su oda «La poesía» (Obras Poéticas, I, pág. 26). 
recurso de modestia del que hace gala en la «Advertencia» al segundo volumen de sus Obras Poéticas?.

Aunque una parte de la crítica coincide en resaltar su labor como escritora de comedias ${ }^{8}$, es en realidad la tragedia, el más elevado entre los géneros clásicos y monopolio exclusivo de varones por tradición dramática, el género que María Rosa Gálvez cultiva con toda su dedicación y el que encuentro personalmente de mayor interés. Sólo el hecho de que se atreva con la tragedia, y no de forma esporádica ni casual sino con una insistencia encomiable, es ya claro síntoma de una heterodoxia visceral que ella va a llevar hasta el interior de sus propias tragedias y que le permite plantear, además, un nuevo concepto de feminidad que excede claramente los límites de la mentalidad ilustrada.

$\mathrm{Su}$ teatro trágico comprende ocho obras; algunas de ellas se avienen al modelo convencional de la tragedia: Alí-Bek ${ }^{9}$, Florinda, Blanca de Rossi, Amnón y La delirante ${ }^{10}$; otras ensayan géneros híbridos, posiblemente de mayor aceptación popular, como el melólogo $S a u^{\prime 11}$-que, a pesar de todo, nunca fue representado-, o los dramas trágicos $S_{a f o}{ }^{12}$ o Zinda $^{13}$-que nunca vio las tablas-, los tres recogidos también en las Obras Poéticas.

${ }^{7}$ Sobre sus obras afirma: «En las mías faltará mucho para la perfección; pero el sexo, y las continuas ocupaciones, y no vulgares penas que acompañan mi situación, no me han permitido limarlas con más escrupulosidad (...). Ni ambiciono una gloria extraordinaria, ni puedo resolverme a creer con tanta injusticia en mis compatriotas, que dexen de tolerar los defectos que haya en mis composiciones con la prudencia que juzgo merece mi sexo. Si me engaña esta esperanza: estoy bien segura de que la posteridad no dexará acaso de dar algun lugar en su memoria á este libro, y con esto al ménos quedarán en parte premiadas las tareas de su autora». (Obras Poéticas. II, págs. 7-8).

${ }^{*}$ Son cinco las comedias que escribe la autora; de ellas, tres se acercan al modelo de la «comedia de costumbres», Un loco hace ciento, La familia a la moda y Los figurones literarios; en otra, El egoista, sigue el modelo de la comedia lacrimosa seria, y, finalmente, Las esclavas amazonas resulta una mezcla algo chocante de comedia sentimental exótica de aventuras con evidentes resabios del teatro áureo. Recuerdo, a propósito de las comedias de Gálvez, la opinión de J.A.Ríos cuando señala, refiriéndose a Los figurones literarios, que la autora «no alcanza la profundidad crítica de Moratín, pero demuestra que por este camino María Rosa Gálvez podría haber encontrado una línea más adecuada a sus verdaderas posibilidades» (pág. 541).

"Ali-Bek fue publicada en el tomo V del Teatro Nuevo Español en 1800 y estrenada el 3 de agosto de 1801 en el Teatro del Príncipe.

${ }^{10}$ Estas cuatro obras trágicas aparecen recogidas en los volúmenes II y III de sus Obras Pó́ticas.

"Saúl se publica en el segundo volumen de sus Obras Poéticas. A ella se refiere J.R. Jones en «Maria Rosa de Gálvez, Rousseau, Iriarte y el melólogo en la España del siglo XVIII» (1996).

${ }^{12}$ Safo se representó en el Coliseo de la Cruz los días 4, 5 y 6 de noviembre de 1801. Se editó como parte del tomo II de sus Obras Poéticas y vio una reedición posterior en 1820 con el título Safo y Faón o el Salto de Leucades (Cádiz, Imprenta de Romero). En 1995 fue reeditada por Doménech junto a Zinda y La familia a la moda y el mismo año la edita Whitaker en Dieciocho.

${ }^{13}$ Publicada en el tomo 11 de las Obras Poéticas y actualmente por F. Doménech (1995). 
Como autora de tragedias, María Rosa Gálvez se sabía rara avis en el panorama de la dramaturgia española. Aunque no es cierto, se señala como «la primera entre las españolas que se ha dedicado a este ramo de literatura $\rangle^{14}$ y presenta el suyo como un trabajo que «en ninguna otra mujer, ni en nación alguna tiene ejemplar, puesto que las más celebradas francesas sólo se han limitado a traducir, o cuando más han dado a luz una composición dramática; mas ninguna ha presentado una colección de tragedias dramáticas como la exponente» ${ }^{15}$. A pesar del orgullo que rezuma de estos y otros escritos donde la autora se refiere a su actividad dramática, María Rosa Gálvez se destaca como una auténtica maestra en el arte de la «captatio benevolentiae» y, así, reconoce su obra como fruto de la inspiración más que como producto de la técnica, señala los impedimentos que su condición femenina y pecuniaria imponen a su relación con las Musas, confiesa sus buenas intenciones al llevar adelante una labor que dice ser «atrevimiento» en su sexo y solicita benevolencia a la hora de juzgarla ${ }^{16}$.

Parece que los críticos de su tiempo, aunque no dudaron en señalar algunos defectos en sus obras, reconocieron por lo general el valor de las mismas; ante el estreno de Ali-Bek en 1801, el Memorial literario señala la excepcionalidad de la autora «a la hora de calzarse el coturno trágico, gloria que al parecer estaba reservada a nuestra nación» ${ }^{17} \mathrm{y}$, ante la aparición de sus Obras Poéticas, el propio Quintana escribe en 1805 en Variedades de Ciencias, Literatura y Artes que «las obras dramáticas de nuestra escritora manifiestan en ella una osadía poco común, una actividad incansable, ingenio para inventar y concebir y facilidad para ejecutar» ${ }^{18}$.

Cinco de estas obras -Ali-Bek, Florinda, Amnón, Blanca de Rossi y La delirante-, forman un único bloque dentro de la producción trágica de la autora, al que llamaré «tragedias de la violencia patriarcal», que se caracterizan, además de por explorar esta misma línea temática, por seguir con bastante fidelidad el modelo de la tragedia neoclásica, añadiendo el consabido componente sentimental. Excepto Ali-Bek, ninguna de las otras cuatro fue representada -publicándose, eso sí, como parte de sus Obras Poéticas-, aunque me atrevo a afirmar que, si lo hubieran sido, no hubieran recibido peores críticas que aquélla. Sería a mi juicio natural que, como Ali-Bek, las tragedias de María Rosa Gálvez tuvieran por lo general buena aceptación crítica, ya que -a excepción de los excesos sentimen-

${ }^{14}$ Así lo hace en la ya citada carta a la Junta de la Dirección de Teatros solicitando el premio para $A l i-B e k$.

${ }^{15}$ Carta ya citada a Carlos IV solicitando subvención para la impresión de sus Obras Poéticus.

16" «Advertencia» al tomo II de sus $O$. Poéticas.

${ }^{17}$ Reseña y crítica recogida por Bordiga (2003), págs. 147-8.

${ }^{18}$ Ibidem, pág. 160. 
tales- se ajustan bastante bien a los preceptos neoclásicos, siendo habitualmente respetuosas con las tres unidades y planteando un conflicto entre el deber y el placer que sabemos absolutamente del gusto neoclásico.

En este sentido, suelen mostrarnos personajes negativos, masculinos o con una falta de sensibilidad propia de éstos - como la Reina Isabel I en La delirante-, dominados por una pasión avasalladora -de tipo sexual o por el poder-, que se enfrenta a la felicidad y a la libertad individual de los personajes femeninos positivos. Todas las obras tienen fondo histórico o bíblico, con elevadas dosis de invención y de adaptación de la historia a las exigencias de la verosimilitud interna de la obra y también todas tienen, de una forma o de otra, un final ejemplar de función catártica. Esto es muy interesante porque, en este final catártico, la muerte de los personajes masculinos negativos o el suicidio o asesinato de los femeninos, y por tanto positivos, tiene como fin el triunfo del concepto de virtud y de sensibilidad que éstos útimos transmiten. En estas obras de Gálvez, la pasión individual ya no se opone directamente al bien comun, como es habitual en la tragedia neoclásica, sino que se opone a la libertad y a la felicidad femeninas, a la sensibilidad y a la virtud de otros individuos concretos que son, además, de un género diferente e históricamente oprimido ${ }^{19}$. Creo que, en este sentido, y como ocurre en las mejores tragedias neoclásicas, las de Gálvez tienen un considerable fondo ético, aunque la escritora malagueña muestre un concepto más moderno y burgués de la felicidad y la sensibilidad como bienes individuales, concepto al que llega a través la denuncia implacable -«poetics of excess», en palabras de E. Franklin Lewis (2004, pág. 105)- de la opresión a la que la sociedad patriarcal ha sometido históricamente a la mujer, más allá de un tiempo y de un espacio concretos.

Esta vocación feminista, allá cuando este término ni siquiera existía, de algunas tragedias de Gálvez, dedicadas a escenificar los diferentes modos de opresión física y psicológica sobre la mujer, ha sido ya suficientemente resaltada por la crítica. Sabemos bien, por ejemplo, a través de los estudios de D. Whitaker (1990, 1992 $)$, que Florinda, Amnón y Blanca de Rossi desarrollan uno de los temas que más preocupaban a la mujer del XVIII -y que Richardson popularizó con su Clarissa-: la agresión sexual, y parece también reveladora la lectura de $L a$

${ }^{19}$ Hacia el cambio de siglo, el conflicto entre individuo y sociedad que la tragedia neoclásica plantea y que no acaba por cierto de resolver, se anima con la aparición de una nueva sensibilidad que entiende que la felicidad común no se sustenta en la anulación de los deseos individuales sino en el respeto a los sentimientos personales y en el correcto ejercicio de la libertad. Como bien ha mostrado J.M. Sala Valldaura (1994) esa sustitución del altruísmo propio de la tragedia neoclásica de primera hornada por el concepto -mucho más decimonónico y burgués- de la felicidad individual como garantía de la felicidad social, y por la exaltación -mucho más romántica- de las pasiones como derecho humano, comienza a intuirse ya antes del cambio de siglo, en tragedias como Solaya o los Circasianos (1770), en las que el asunto moral prevalece claramente sobre el tema político. 
delirante que realiza el estudioso norteamericano (1992b,1993a), resaltando la locura de Leonor, hija de María Estuardo, como metáfora de la opresión masculina sobre la mujer. El tema de la «posesión» masculina y de la mujer como objeto vendible, transferible e intercambiable por la propiedad patriarcal, es también el tema de la primera -y casi nada estudiada- de las tragedias de la autora, Ali-Bek; en ella, la esclava europea Amalia, apenas logra encontrar un lugar propio entre dos hombres, «soberanos del sexo» -dice la tragedia-, el Bey de Egipto y el Bey de Alejandría, que se la disputan como una mercancía, y un padre absolutamente repugnante, que la vendió sin miramientos y que trata ahora de recuperarla para acallar su conciencia. Aunque al final Amalia logre su libertad, resulta bastante poco esperanzador que haya de suplicar por ella, y que sea precisamente uno de los hombres que pretenden poseerla quien se la conceda; creo que este final resume bastante bien el núcleo ideológico que unifica estas «tragedias de la violencia patriarcal» y que apunta a denunciar el control masculino sobre la libertad y la felicidad de las mujeres.

Pero, más allá de estas obras de denuncia directa y explícita, me parecen más interesantes aquellas en las que la autora subvierte el fondo ideológico de la tragedia para proporcionar -siempre sin exponerse demasiado- unas claves nuevas en la interpretación de la función de lo femenino en el nuevo siglo que entraba. Dos son, a mi juicio, las «utopías de lo femenino» que nos ha dejado María Rosa Gálvez, y ninguna de las dos responde por cierto al modelo de la tragedia como tal: Zinda, drama trágico en tres actos y Safo, drama trágico en un acto, a mi juicio la obra más interesante y reveladora de cuantas escribió la autora.

Zinda está ambientada en el Congo, y parte de la recreación libre de la fígura de la reina Jinga de Ngongo, actual Angola, donde ésta lideró a los Mbungu durante cuarenta años en pleno siglo XVII. Es evidente, con este punto de partida tan poco convencional, que la obra no podía seguir el molde de la tragedia tradicional como las anteriores. Los estudiosos que se han ocupado de ella han ensayado diferentes etiquetas: «comedia dramática», dice F. Doménech (1995, pág. 33), editor de la obra, vinculándola a la «comedia sentimental», a caballo entre la «tragedia de desenlace feliz» y la «comedia seria», la sitúa R. Andioc (2001, pág. 47), mientras que $\mathrm{V}$. Trueba propone un análisis más detenido que ilumine sus relaciones con la «comedia lacrimosa» (2002, pág. 432). Llamémosla como queramos, es más que evidente que Zinda se inserta a la perfección en ese espacio de indefinición dramática señalado más arriba, a caballo entre las dos centurias, en el que sobre el modelo de la tragedia neoclásica se superponen elementos más propios del gusto del nuevo siglo, como son los resortes del teatro sentimental y la nueva ideología burguesa.

En este sentido, Zinda es un perfecto alegato antiesclavista es un momento histórico en que el debate sobre la necesidad de humanización de los excesos del 
colonialismo europeo era asunto candente. La obra dramatiza el enfrentamiento entre el colonialismo salvaje, que en la obra representa el malvado holandés Vínter, y la autodefensa orgullosa de los pueblos primitivos, representada por la reina Zinda, su marido Nelzir y todo el resto de guerreros negros de la tribu, y propone, como solución intermedia, el colonialismo respetuoso y beneficioso para ambas partes que encarna Pereyra, comandante del fuerte portugués en tierras congoleñas. De este modo, después de las numerosas perfidias ideadas por Vínter para deshacerse de Pereyra, desposar a la fuerza a su hija, tomar el control del fuerte, y obligar a Zinda, mediante el secuestro del pequeño Zélido, a entregar las riquezas de su tierra, el equilibrio acaba siendo restituido gracias a la rectitud moral y al coraje de Zinda y también a la nobleza de Pereyra, que construyen juntos un territorio de paz colonizado, cristiano y respetuoso con la libertad de todos.

No insistiré en el asunto abolicionista, suficentemente tratado por E. Franklin Lewis (1997) y por V. Trueba (2002) en sus artículos sobre esta obra, que inciden en la novedad que un texto de esta índole suponía en la dramaturgia española del XVIII. Me interesa más resaltar el valor que el asunto cobra en la pluma de una mujer consciente, como María Rosa Gálvez, de la desigualdad que presidía el panorama social de su época. De hecho, que una mujer pretenda incidir de esta forma desde las tablas en el derecho de todos a ser respetados, a ser tratados con justicia y a que se garantice su libertad, no puede ser ni mucho menos casual y creo que la transferencia subrepticia de la reivindicación antiesclavista a la feminista se realiza precisamente a través del personaje de la negra Zinda.

Zinda, la reina negra del Congo, reúne en sí rasgos que la convierten, a mi entender, en la heroína más original, más acertada y también posiblemente más entrañable por lo disparatada, de cuantas nos ha dejado - y no han sido pocasMaría Rosa Gálvez. Zinda es mujer y negra, lo cual parece situarla de partida en la marginalidad más absoluta dentro del proyecto patriarcal ilustrado; pero se da el caso de que es, además, reina y guerrera, y esto le confiere súbitamente dignidad y poder y la devuelve al centro del patriarcado, desde el cual ella manda, instruye y da ejemplo a sus súbditos, que casualmente son todos hombres y también guerreros. Por si corría algún peligro de ser confundida con el prototipo de la mujer «varonil» tan vapuleada por la crítica ilustrada y que tanto levantó los ánimos de la cazuela, Zinda aparece además imbuida con los rasgos más característicos de la feminidad, como esposa de Zefir y madre amante de Zélido, y presenciamos escenas de respeto conyugal y de amor maternal que no dejan la menor duda acerca de la naturaleza femenina de la heroína ${ }^{20}$.

${ }^{20}$ Como bien estudia R. Fernández Cabezón (2003), entre 1780 y 1790 se produce un florecimiento de la comedia heroica barroca que, acomodada a los gustos del nuevo público dieciochesco, se centra en la defensa de los grandes ideales patrióticos a través de las hazañas bélicas y de los lances 
Pero lo sorprendente es que, además de reina guerrera y negra, madre y esposa, Zinda es ilustrada y cristiana. Si su sensibilidad podría achacarse, sin necesidad de más explicación, a su naturaleza femenina, parece no ocurrir lo mismo con su tolerancia, su virtud y su nobleza en la protección del bien común, que parecen provenir, como su piedad cristiana, del magisterio civilizador de Pereyra.

Dejaremos a un lado el hecho de que la naturaleza «salvaje» de Zinda haya sido «civilizada» por Pereyra, lo cual da para lecturas bastante poco halagüeñas del concepto que Gálvez tiene de la adscripción femenina al mundo de la razón. Es evidente que Gálvez no violenta el concepto centralista por el que la razón ilustrada se perfila como patrimonio europeo y masculino, pero lo importante es que también deja claro que no hay razón para que no deje de serlo. Zinda es el mejor ejemplo de que valor y sensibilidad, honor y piedad, razón y feminidad no son excluyentes como parecía extraerse del pensamiento ilustrado, y nos lo demuestra en una obra que trata fundamentalmente de deshacer esteretotipos: si no todos los blancos son tiranos, como parece creer el guerrero negro Alcaypa, ni todos los negros son salvajes, como parece suponer Vínter, ni el colonialismo ha de ser siempre negativo y destructor, ¿por qué entonces habría de ser necesariamente el espacio femenino exclusivamente el de la sensibilidad y no el de la razón?.

Creo que Zinda es una metáfora asombrosamente lúcida de esa utopía femenina que la autora nos va desgranando a lo largo de sus tragedias, utopía a través de la cual trata de ofrecer un modelo femenino que exceda los límites tan estrechos que le reservó el pensamiento ilustrado y aúne rasgos hasta entonces incompatibles.

En este sentido, Zinda, la reina negra ilustrada del Congo, es un hallazgo sin parangón en la dramaturgia española de la época, y me parece además que marca perfectamente la transición entre el pensamiento ilustrado y las nuevas ideas de libertad que traía el siglo entrante. De hecho, un personaje como Zinda, mujer negra e ilustrada, sólo podía existir desde los márgenes temporales de la Ilustración y nunca desde su centro neurálgico. El hecho de que Zinda esté ahí es el mejor indicio de que los tiempos permitían que algunas mujeres, como María Rosa Gálvez, avistaran el desmoronamiento de los grandes mitos sobre la feminidad que construyó la Ilustración y contribuyeran a él con los medios disponibles.

espectaculares en escena. No pocos dramaturgos (José Concha, Antonio Valladares y Sotomayor, Luis Moncín, Manuel Fermín de Laviano, Fermín del Rey, Luciano Comella, Gaspar Zavala y Zamora, etc.) eligen como protagonistas a mujeres guerreras, cuyas características fundamentales son el valor, la lucha por la libertad, la lealtad al rey, un elevado concepto del honor y la defensa de la religión católica. Muy bien recibidas por el público femenino de la cazuela, estas heroínas solían recibir el calificativo admirativo de «varoniles» o ser comparadas con las amazonas. Por supuesto, no fueron del gusto de los críticos ilustrados porque su heroísmo femenino atentaba claramente contra la poética clasicista y también porque cuestionaba la autoridad masculina. 
Algo similar ocurre con Safo, que, pese a su brevedad y al poco interés que la crítica ha mostrado en ella ${ }^{21}$, es sin duda la obra ideológicamente más moderna y comprometida de cuantas escribió la autora. En ella dramatiza los últimos momentos y el suicidio de Safo de Lesbos, enamorada de Faón y abandonada por éste, desde el acantilado de la isla de Leucadia. Para ello se inspira en la leyenda amorosa entre Safo y Faón narrada por Ovidio, y más directamente en la obra de Étienne F. Lantier Voyages d'Antenor en Grèce et en Asie (1797), de la cual toma ideas e incluso algunos pasajes (Bordiga 2003).

Parece haber un cierto acuerdo crítico acerca de la conjunción en esta obra de los esquemas formales del neoclasicismo -cumplimiento de las unidades, uso del romance heroico- con elementos formales propios de la retórica del primer romanticismo, especialmente en los primeros versos del drama, donde no queda lugar a dudas de que el paisaje nocturno y la naturaleza hostil, reflejo del tormento interior que sufre la protagonista, anuncian ya una nueva estética ${ }^{22}$. Así lo han señalado, de hecho, cuantos han hecho referencia, aunque de pasada, a esta obra ${ }^{23}$, algunos - como D. Whitaker-indicando incluso la presencia de aspectos románticos «de fondo» que no obtienen, sin embargo, un análisis más exhaustivo: el tema del amor imposible, la rebelión contra las normas sociales o el suicidio, a los que yo añadiría, posiblemente, otros más como la «suerte» hostil, la arbitrariedad de la autoridad paterna, el amor que vence a la muerte, la falta de visión cristiana y, fundamentalmente, la exaltación de la libertad individual.

Aunque no es éste quizá el momento de llevar a cabo un análisis exhaustivo de esta obra, me interesa, no obstante, resaltar la concurrencia, evidentemente no casual, entre la aparición en esta obra de esos elementos más propios ya de una ideología romántica que neoclásica y el diseño de una heroína trágica fuera de los límites habituales de contención de la autora, que ofrece una imagen de lo feme-

${ }^{21}$ Hasta ahora, Doménech (1995), Andioc (2001), Bordiga (2003) y Franklin (2004) le han dedicado a esta obra unas brevísimas páginas dentro del marco general de sus trabajos.

${ }_{22}^{22}$ Noche desoladora, fiel imagen

De mis continuos bárbaros tormentos;

No cese tu rigor, no tus furores:

El hórrido silbido de los vientos,

El rayo desprendido de la esfera,

El ronco son del pavoroso trueno

Halaga un corazón desesperado.

(...) ¡Espantosa quietud! Todo enmudece,

$\mathrm{Y}$ al tormentoso horror sigue el silencio.

Las negras furias que mi amor persiguen,

Me privan hasta del bárbaro consuelo

De ver el orbe vacilar al choque

De los embravecidos elementos.» (O. Poéticas, tomo II, pág. 24)

${ }^{23}$ Sebold (1983), Whitaker (1993b), Ruiz Ramón (1979). 
nino bastante más arriesgada de lo que se atreve a hacer en otras obras. Si Safo, que fue aprobada por la censura ${ }^{24}$ y representada durante tres días en noviembre de 1801, no suscitó ninguna suspicacia fue, en mi opinión, porque rezuma una ambigüedad que permite perfectamente interpretarla en una línea de didactismo y ejemplo moral acorde con los intereses del poder religioso e ilustrado.

Creo que la clave para entender adecuadamente Safo se encuentra, precisamente, en realizar una lectura palimséstica que nos permita valorar en su justa medida el contenido didáctico de la obra. Señala J. Bordiga al respecto que el objetivo de $\mathrm{M}^{\mathrm{a}}$ Rosa Gálvez en esta obra es el de transmitir los peligros y desilusiones a que se halla expuesta una mujer que no controla sus pasiones (pág. 82), y Whitaker, por su parte, identifica en ella el «utile dulci» típicamente neoclásico cuando afirma que este drama señala los peligros de la pasión incontrolada (pág. 28). Aunque estoy de acuerdo con ambos, creo también que el contenido subversivo de la obra rebasa, con mucho, al didáctico.

Tengamos en cuenta, para empezar, que Safo es ejemplo de la incursión exitosa de la mujer en el mundo de la razón. Safo es, como se reconoce en la propia obra, escritora respetada y laureada en su tiempo ${ }^{25}$, y ejemplo de quehacer literario femenino para la posteridad. Pero Safo es también una mujer libre, la única heroína verdaderamente libre de los estereotipos patriarcales que nos presenta la autora en toda su producción. De hecho, Safo no es presentada como hija, ni como esposa, ni como propiedad de nadie. Safo es un sujeto femenino libre para desear a Faón con una pasión de sensualidad desbordante - y, por cierto, alejada del romanticismo virtuoso y descafeinado al uso en las féminas de la época-, libre para disfrutarlo fuera de las normas convencionales y libre para renunciar a cualquier cosa - al nombre, a la patria, al reconocimiento social-por él. Safo expresa libre y espontáneamente sus sentimientos individuales y, en este sentido, precede a esas heroínas sinceras y apasionadas del Romanticismo que, al estilo de las de G. Sand, vocearán una ardiente revuelta contra la sociedad, el mundo y las reglas tradicionales de la moral. No en vano Safo, y la unión de talento poético y cualidades emocionales que esta representa, serán foco de atención de no

${ }^{24}$ La aprobación de Santos Díez y la eclesiástica de J. B. de Ezpeleta y B. Muñoz de Torres, recogidas poe Bordiga (2003, pág. 157).

2.5 «NICANDRO

¿Qué he escuchado?

¿La poetisa Safo á tal extremo

Reducida se ve? ¿La que de Atenas

Mereció los aplausos y los premios?

¿Por la que suspiraron vanamente

Millares de rendidos, y yo entre ellos?» (O.P., pág. 37) 
pocas escritoras románticas (Carolina Coronado, Gertrudis Gómez de Avellaneda, Rogelia León, etc. $)^{26}$.

La pasión de la Safo de Gálvez por Faón no es una cárcel de amor retórica o impuesta, sino el amor que siente una mujer por un hombre, y la «tirana suerte» de la poetisa no es otra cosa que la vieja enfermedad de desamor que viene del sentimiento no correspondido. Safo quiere ser amada por Faón y, ante la imposibilidad conseguirlo, ejerce su último acto de libertad en el suicidio, por supuesto sin arrepentimiento ni piedad, todo lo contrario, maldiciendo a Faón e incitando a las demás mujeres a la rebelión y a la venganza:

Considero

cuánta es la diferencia de mi suerte por un traidor amante. En otro tiempo sólo al nombre de Safo resonaba con vivas repetidos el Liceo de la célebre Atenas, y a mi vista aplausos tributaba todo un pueblo: hoy a verme morir otro se junta, lleno de compasión, de dolor lleno. ¿Y por qué enternecidos al mirarme lágrimas derramáis Yo nada siento. ¿Qué pudiera sentir cuando el sepulcro a mis desgracias se presenta abierto? Aquél es. ¡Oh mujeres de Leucadia! (...) Vosotras que miráis en mí el ejemplo de la negra perfidia de los hombres, abominad su amor, aborrecedlos; pagad sus rendimientos con engaños, pagad su infame orgullo con desprecios; giman a vuestros pies; vengadme todas; humillad para siempre esos soberbios. $\mathrm{Y}$ tú, ingrato Faón, hombre nacido por mi fatalidad, plegue a los cielos que mi sombra interrumpa tu reposo, que la tierra te niegue el alimento, que cl sol te oprima, y que la muerte arranque de tus aleves brazos el objeto que causa tu perfidia, y que a tus ojos muera, del mismo modo que yo muero. (O.P., II, págs. 50-1)

El suicidio de Safo, simbólicamente representado en esa zambullida en el mar desde lo alto de la isla de Leucadia, no es sino su particular forma de mostrar

2h Cfr. Kirkpatrick (1990) y Mayoral (1990). 
su rebeldía femenina ante el mundo que la rodea, ante la conjunción de elementos adversos que hacen su amor por Faón imposible. En este sentido, aparte de visceralmente romántico, el de Safo es el suicidio más heterodoxo de toda la obra de Gálvez, cuyas heroínas se quitan la vida para salvaguardar la fidelidad conyugal (Blanca de Rossi) o para purgar sus culpas (Florinda), pero no para afirmar su amor y a sí mismas.

Acostumbrados como nos tiene Gálvez a mujeres oprimidas y vacías de amor como las que nos dibuja en sus tragedias (Amalia, Florinda, Thamar) y a otras cuyo amor conyugal y maternal es absolutamente teatral (como el de Zinda), esta pasión de Safo, tan de carne y hueso, es el mejor tributo que podía rendir la autora a la mujer de su tiempo. Desmitificar esa femineidad, sensible y virtuosa, y añadirle la capacidad de ejercer la razón o de amar con verdadera pasión, es una tarea necesaria pero ingrata en la época en la que escribe Gálvez. No olvidemos que, por aquellas mismas fechas, un dinosaurio ideológico de la talla de J.N. Böhl de Faber le escribía a Frasquita Ruiz de Larrea lo siguiente, para justificar su ruptura matrimonial acaecida en 1806:

La esfera intelectual no se ha hecho para las mujeres. Dios ha querido que el amor y el sentimiento sean su elemento (...) ¿Por qué son desgraciadas todas las mujeres sabias? ¿por qué se las detesta? ¿Por qué se las ridiculiza, por lo menos? No he encontrado todavía una mujer a quien la más pequeña superioridad intelectual no produzca alguna deficiencia moral. El día que quemes tus «Rights of women» será para mí un gran día ${ }^{27}$.

Supongo que esa «deficiencia moral» a la que se refiere Böhl de Faber sería la que la censura vio en la pasión desenfrenada de Safo, cuyo suicidio le debió de parecer extremadamente aleccionador por intelectual, por disoluta y por pagana. Creo que María Rosa Gálvez supo manejar con extraordinaria habilidad dramática la ambigüedad de la obra, cuya interpretación «ortodoxa» en la línea más didáctica garantizaba a la vez su representabilidad. Sin embargo, desde una perspectiva actual, no se nos escapa la forma tan sutil en la que Safo persigue su voluntad hasta el final ni la afirmación final de su pasión por encima de todos los obstáculos, ni podemos dejar de ver en su muerte, más que el castigo ejemplar, el triunfo de un espíritu libre que se lleva al sepulcro, por cierto, el amor recobrado de Faón por encima de la voluntad del padre tirano.

He tratado de mostrar, en estas páginas, que el teatro trágico de María Rosa Gálvez se desarrolla en un momento de transición en la historia de España en el que, sobre las ideas ilustradas de razón y sensibilidad, se superponen nuevos conceptos que, se llamen prerrománticos o se vinculen con la nueva ideología

${ }^{27}$ Recogido por A. Orozco Acuaviva (1977), pág. 226. 
burguesa, sirven en cualquier caso de sustento para el feminismo que anima el proyecto literario de la autora. La libertad y la felicidad de la mujer, la tolerancia a la diversidad, una feminidad más moderna y menos enraizada en la biología, la razón como patrimonio también femenino, son algunas de las ideas que emergen, si no siempre del texto explícito de las obras trágicas de Gálvez, al menos sí de una lectura de su subtexto atenta a las estrategias a través de las cuales la autora muestra su disidencia del pensamiento oficial ilustrado sobre la mujer.

Recojo, para concluir, unas palabras de Inés Joyes Blake, en la «Apología de las mujeres» que sigue a su traducción de El príncipe de Abisinia de Samuel Johnson realizada en el cambio de siglo (1798, pág. 175), donde se observa perfectamente su coincidencia con María Rosa Gálvez, tanto en el rechazo a la mitificación histórica de la mujer, como en el planteamiento de la «utopía» femenina, de ese nuevo papel que la mujer debía desempeñar en el siglo XIX, una vez ya había sido iluminada, aunque fuera de refilón, por las «luces» ilustradas:

No puedo sufrir con paciencia el ridículo papel que generalmente hacemos las mujeres en el mundo, unas veces idolatradas como deidades y otras despreciadas aun de hombres que tienen fama de sabios (...) Yo quisiera desde lo alto de algún monte donde fuera posible que me oyesen todas darles un consejo. Oíd, mujeres, les diría, no os apoquéis: vuestras almas son iguales a las del sexo que os quiere tiranizar: usad las luces que el Criador os dio: a vosotras, si queréis, se podrá deber la reforma de las costumbres, que sin vosotras nunca llegará: respetaos a vosotras mismas y os respetarán: amaos unas a otras (...): viviréis felices cuanto cabe en el mundo, y moriréis con la gloria de dejar una posteridad virtuosa. 


\section{BIBLIOGRAFÍA}

Alborg, Juan L., 1972. Historia de la Literatura Española, Vol. III, Madrid, Gredos.

ANGUlo EGEA, María, 2002. «Fingir y aparentar. La imagen de las mujeres en el teatro sentimental de Luciano Francisco Comella (1751-1812)», Dieciocho, XXV, 2, págs. 281-302.

BORDiga GrinsteIN, Julia, 1996. Dramaturgas españolas de fines del siglo XVIII y principios del XIX. El caso de Maria Rosa de Gálvez, UMI Dissertation Services, Ann Arbor, Michigan.

2002. «Panorama de la dramaturgia femenina española en la segunda mitad del siglo XVIII y principios del siglo XIX», Dieciocho, XXV, 2, págs. 195218.

2003. La rosa trágica de Málaga: vida y obra de María Rosa de Gálvez. Dieciocho, XXVI, 1, Anejos de Dieciocho, 3.

CAINE, Barbara, y SLUGA, Glenda, 2000. Género e Historia. Mujeres en el cambio sociocultural europeo de 1780 a 1920, Madrid, Narcea.

CEJADOR Y FRAUCA, Julio, 1917. Historia de la lengua y la literatura castellana, Tomo VI, Madrid, Tipografía de la Revista de Archivos, Bibliotecas y Museos, 1915-1927.

COCA, Fátima, 2000. «La influencia de la 'comedia sentimental' en la poética del 'drama histórico' y de la 'tragedia neoclásica' a principios del siglo XIX en España », Cuadernos de Ilustración y Romanticismo, 8, págs. 115-130.

CoOK, John A., 1974. Neo-classic drama in Spain. Theory and Practice, Dallas, Southern Methodist UP.

EzQuerra del Bayo, Joaquín, y Luis PÉrez Bueno, 1924. Retratos de mujeres españolas del siglo XIX, Madrid, Imprenta de Julio Cosano.

FERNÁNDEZ CABEzón, Rosalía, 2003. «La mujer guerrera en el teatro español de fines del siglo XVIII». Anuario de Estudios Filológicos, XXVI, págs. 117-136.

FERnÁndez Quintanilla, Paloma, 1981. La mujer ilustrada en la España del siglo XVIII, Madrid, Ministerio de Cultura.

FRANKLIN LEWIS, Elizabeth, 1996. «The Tearful Reunion of Divided Feminity in María Rosa Gálvez's Neoclassic Theatre», Letras Peninsulares, IX, 2-3, págs. 205-216.

1997. «Breaking the Chains: Language and the Bonds of Slavery in María Rosa Gálvez's Zinda (1804)», Dieciocho, XX, 2 (fall), págs. 263-275.

2004. «Cyring out for Feminine (Un)Hapiness: María Rosa Gálvez's Search for Sapphic Immortality», en Women Writers in the Spanish Enlightenment. The Pursuit of Hapiness, Hants, England, Burlington Vt., Ashgate Pub., págs. 97-152. 
FroldI, Rinaldo, 2004. «La tragedia Blanca de Rossi de Ma Rosa Gálvez», Dieciocho, 27,1, págs. 157-170.

GÁlveZ, Ma Rosa. (La lista completa de obras manuscritas e impresas: en F. Aguilar Piñal, 1986. Bibliografia de autores españoles del siglo XVIII. Madrid, CSIC, tomo IV; también en J. Bordiga Grinstein, La rosa trágica de Málaga: vida y obra de María Rosa de Gálvez, Dieciocho, XXVI, 1, Anejos de Dieciocho, 3.)

1801. Ali-Bek, La bella labradora y Un loco hace ciento. Teatro Nuevo Español, (6 vols.), vol. V, Madrid, Oficina de Benito García y Cía.

1804. Obras poéticas, 3 vols. Madrid, Imprenta Real.

(s.a.). Las esclavas amazonas. (Biblioteca Nacional de Madrid, Mss. 16507 y 17196; Biblioteca Municipal de Madrid, Mss. 1-28-14).

1995. Safo, Daniel Whitaker (ed.), Dieciocho, 18, 2, págs. 189-210.

1995. Safo. Zinda. La familia a la moda, Fernando DOMÉNECH (ed.), Madrid, Asociación de Directores de Escena de España.

2001. La familia a la moda, René ANDIOC (ed.), Salamanca, Plaza Universitaria. García Lorenzo, Luciano (ed.), (2000). Autoras y actrices en la historia del teatro español, Murcia, Universidad.

Guillén RoBles, F., 1874. Historia de Málaga y su provincia. Málaga, Imprenta de Rubio y Cano.

Hormigón, Juan A. (coord.), 1995. Autoras en la historia del teatro español (1500-1994), vol.I, Madrid, Asociación Directores de Escena.

JONES, Joseph R., 1995. «María Rosa de Gálvez: Notes for a Biography», Dieciocho, 18,2 (fall), págs. 173-186.

1996. «María Rosa de Gálvez, Rousseau, Iriarte y el melólogo en la España del siglo XVIII», Dieciocho, 19,2 (fall), págs. 165-179.

JOYES Y BLAKE, Inés, 1798. «Apología de las mujeres» en El príncipe de Abisinia, Samuel JOHNSON (trad.), Madrid, Sancha.

KIRKPATRICK, Susan, 1990. «La 'hermandad lírica' de la década de 1840», en Marina MAYORAL (coord.), Escritoras románticas españolas, Madrid, Fundación Banco Exterior, págs. 25-42.

KITTS, Sally-Ann, 1995. The debate on the Nature, Role and Influence of Woman in Eighteenth-Century Spain, Lewiston, Edwin Mellen Press.

LAFARGA, Francisco, 1893-1988. Las traducciones españolas del teatro francés, 1700-1835, Barcelona, Publicaciones de la Universidad.

MAYORAL, Marina, 1990. «Las amistades románticas: confusión de fórmulas y sentimientos», en Escritoras románticas españolas, Madrid, Fundación Banco Exterior, págs. 37-45.

Molina PETIT, Cristina, 1993. Dialéctica feminista de la Ilustración, Barcelona, Anthropos, Madrid/Comunidad. 
NELKEN, Margarita, 1930. Las escritoras españolas. Barcelona, Labor.

OrozCO ACUAVIVA, A., 1977. La gaditana Francisca Larrea, primera romántica española, Jerez.

PALACIOS FERNÁNDEZ, Emilio, 2000. «Noticia sobre el Parnaso dramático femenino en el siglo XVIII», en Luciano GARCÍA LORENZO (ed.), Autoras y actrices en la historia del teatro español, Universidad de Murcia \& Universidad de Castilla-La Mancha, págs. 83-131.

2002. La mujer y las letras en la España del siglo XVIII, Madrid, Ediciones del Laberinto.

Ríos CARratalÁ, Juan A., 1995. «María Rosa Gálvez», en G. CARNERo (coord.), Historia de la Literatura Española, t.7, Madrid, Espasa-Calpe, págs. 539541.

Rudat, Eva Ma Kahiluoto, 1986. «María Rosa Gálvez de Cabrera (1768-1806) y la defensa del teatro neoclásico», Dieciocho, 9, págs. 238-248.

Sala VAlldaura, J. M ${ }^{\mathrm{a}}$., 1994. «La felicidad social como virtud en la tragedia neoclásica», Castilla, 19, págs. 171-186.

SERRANO Y SANZ, Manuel, 1975. Apuntes para una biblioteca de escritoras españolas desde el año 1401 al 1833, Madrid, Sucesores de Rivadeneyra, 19031905, 4 vols. (facsímil, Madrid, Atlas, 1975).

Sullivan, Constance, 1997. «Las escritoras del siglo XVIII», en Iris M. ZAVALA (coord.), Breve historia feminista de la literatura española, vol. IV, Barcelona, Anthropos, págs. 305-330.

Trueba MirA, Virginia, 2002. «Paradojas de la alteridad en Zinda de Rosa Gálvez». IV Congreso Internacional de Teoría del Teatro. Theatralia, 4, págs. 427-452.

WHITAKER, Daniel S., 1988. «Los figurones literarios of María Rosa Gálvez as a enlightened response to Moratín's La comedia nueva», Dieciocho, 11,1 (spring), págs. 3-14.

1990. «Darkness in the age of light: Amnón of María Rosa Gálvez», Hispanic Review, 58 (autumn), págs. 439-453.

1992". "Clarissa's sister: The Consequences of Rape in Three Neolassic Tragedias of María Rosa Gálvez», Letras Peninsulares, 5,2 (fall), págs. 239-251.

1992b. «La mujer ilustrada como dramaturga: el teatro de María Rosa Gálvez», en Actas del X Congreso Internacional de Hispanistas, Barcelona, págs. 1551-1562.

1993a. «Absent Mother, Mad Daughter and the Therapy of Love in La delirante of María Rosa Gálvez», Dieciocho, XVI, 1-2 (Spring-fall), págs. 167-176.

1993b. «An Enlightened Premiere: The Theatre of María Rosa Gálvez», Letras Femeninas, 1-2, págs. 21-32. 
Zorrozua SANTIESTEBAN, $\mathrm{M}^{\mathrm{a}}$ del Pilar, 1999. Escritoras de la Ilustración española (1759-1808), Bilbao, Dpto. Publicaciones Universidad Deusto (microforma). 